NASA/TM-2007-214940
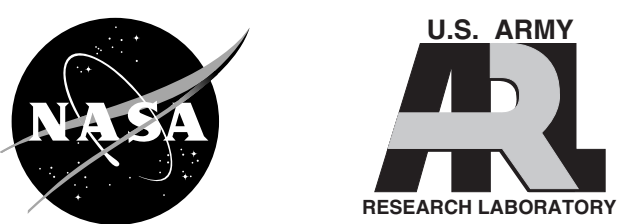

\title{
Resilient Propulsion Control Research for the NASA Integrated Resilient Aircraft Control (IRAC) Project
}

Ten-Huei Guo

Glenn Research Center, Cleveland, Ohio

Jonathan S. Litt

U.S. Army Research Laboratory, Glenn Research Center, Cleveland, Ohio 


\section{NASA STI Program . . . in Profile}

Since its founding, NASA has been dedicated to the advancement of aeronautics and space science. The NASA Scientific and Technical Information (STI) program plays a key part in helping NASA maintain this important role.

The NASA STI Program operates under the auspices of the Agency Chief Information Officer. It collects, organizes, provides for archiving, and disseminates NASA's STI. The NASA STI program provides access to the NASA Aeronautics and Space Database and its public interface, the NASA Technical Reports Server, thus providing one of the largest collections of aeronautical and space science STI in the world. Results are published in both non-NASA channels and by NASA in the NASA STI Report Series, which includes the following report types:

- TECHNICAL PUBLICATION. Reports of completed research or a major significant phase of research that present the results of NASA programs and include extensive data or theoretical analysis. Includes compilations of significant scientific and technical data and information deemed to be of continuing reference value. NASA counterpart of peer-reviewed formal professional papers but has less stringent limitations on manuscript length and extent of graphic presentations.

- TECHNICAL MEMORANDUM. Scientific and technical findings that are preliminary or of specialized interest, e.g., quick release reports, working papers, and bibliographies that contain minimal annotation. Does not contain extensive analysis.

- CONTRACTOR REPORT. Scientific and technical findings by NASA-sponsored contractors and grantees.
- CONFERENCE PUBLICATION. Collected papers from scientific and technical conferences, symposia, seminars, or other meetings sponsored or cosponsored by NASA.

- SPECIAL PUBLICATION. Scientific, technical, or historical information from NASA programs, projects, and missions, often concerned with subjects having substantial public interest.

- TECHNICAL TRANSLATION. Englishlanguage translations of foreign scientific and technical material pertinent to NASA's mission.

Specialized services also include creating custom thesauri, building customized databases, organizing and publishing research results.

For more information about the NASA STI program, see the following:

- Access the NASA STI program home page at http://www.sti.nasa.gov

- E-mail your question via the Internet to help@sti.nasa.gov

- Fax your question to the NASA STI Help Desk at 301-621-0134

- Telephone the NASA STI Help Desk at 301-621-0390

- Write to: NASA Center for AeroSpace Information (CASI) 7115 Standard Drive Hanover, MD 21076-1320 
NASA/TM-2007-214940

ARL-TR-4131
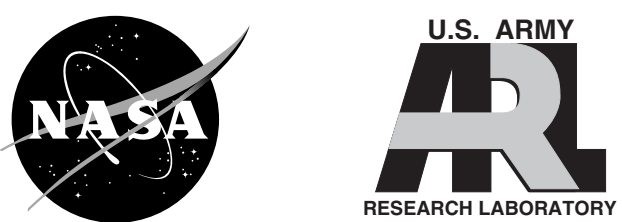

\section{Resilient Propulsion Control Research for the NASA Integrated Resilient Aircraft Control (IRAC) Project}

Ten-Huei Guo

Glenn Research Center, Cleveland, Ohio

Jonathan S. Litt

U.S. Army Research Laboratory, Glenn Research Center, Cleveland, Ohio

Prepared for the

Infotech@Aerospace 2007 Conference and Exhibit

sponsored by the American Institute of Aeronautics and Astronautics

Rohnert Park, California, May 7-10, 2007

National Aeronautics and

Space Administration

Glenn Research Center

Cleveland, Ohio 44135 
Level of Review: This material has been technically reviewed by technical management.

Available from

NASA Center for Aerospace Information

7115 Standard Drive

Hanover, MD 21076-1320
National Technical Information Service 5285 Port Royal Road Springfield, VA 22161

Available electronically at http://gltrs.grc.nasa.gov 


\title{
Resilient Propulsion Control Research for the NASA Integrated Resilient Aircraft Control (IRAC) Project
}

\author{
Ten-Huei Guo \\ National Aeronautics and Space Administration \\ Glenn Research Center \\ Cleveland, Ohio 44135 \\ Jonathan S. Litt \\ U.S. Army Research Laboratory \\ Glenn Research Center \\ Cleveland, Ohio 44135
}

\begin{abstract}
Gas turbine engines are designed to provide sufficient safety margins to guarantee robust operation with an exceptionally long life. However, engine performance requirements may be drastically altered during abnormal flight conditions or emergency maneuvers. In some situations, the conservative design of the engine control system may not be in the best interest of overall aircraft safety; it may be advantageous to "sacrifice" the engine to "save" the aircraft. Motivated by this opportunity, the NASA Aviation Safety Program is conducting resilient propulsion research aimed at developing adaptive engine control methodologies to operate the engine beyond the normal domain for emergency operations to maximize the possibility of safely landing the damaged aircraft. Previous research studies and field incident reports show that the propulsion system can be an effective tool to help control and eventually land a damaged aircraft. Building upon the flight-proven Propulsion Controlled Aircraft (PCA) experience, this area of research will focus on how engine control systems can improve aircraft safe-landing probabilities under adverse conditions. This paper describes the proposed research topics in Engine System Requirements, Engine Modeling and Simulation, Engine Enhancement Research, Operational Risk Analysis and Modeling, and Integrated Flight and Propulsion Controller Designs that support the overall goal.
\end{abstract}

\section{Introduction}

On July 19, 1989, the center, tail-mounted engine of a United Airlines (UAL) DC-10 suffered an uncontained failure in flight, which resulted in the loss of all hydraulic systems as well as airframe damage (ref. 1). Using differential engine thrust alone, the crew was able to fly the crippled aircraft to the Sioux City, Iowa airport, where they successfully crash landed it. Although the resulting impact and flames claimed many victims, the fact that there were any survivors at all is a testament to the heroic actions of the crew, who managed to regain and maintain control of the plane without the use of the flight control surfaces. Similar loss-of-hydraulics situations have not had favorable outcomes, and in fact the only case of an in-service jet airliner of this type to land safely without any hydraulics has been the recent DHL shootdown incident in Baghdad (ref. 2).

NASA has traditionally made aviation safety one of its major research missions and the Sioux City accident, along with the pilots' recovery strategies, has been influential. Recognizing the importance of the role of the propulsion system in the operation of a damaged aircraft, NASA initiated the Propulsion Controlled Aircraft (PCA) research effort in the early 1990's (ref. 3). A PCA system that used pilotsupplied flight-path command inputs and airplane sensor feedback parameters to generate appropriate engine thrust commands for emergency flight operation was demonstrated successfully. This PCA system requires no modification to the engine or engine control system. The Throttles-Only Control (TOC), where the pilot maneuvered the airplane using only the throttles, was demonstrated over a wide range of commercial and fighter aircraft (ref. 4). These demonstrations pointed out the maneuverability issues resulting from slow engine response and the high level of pilot workload required during landing. 
In response to the potential Man Portable Air Defense System (MANPADS) threat to commercial airliners, NASA launched the "Damage Adaptive Control System (DACS)" project in the early 2000's under the Aviation Safety and Security Program. The objective of the DACS project was to find possible solutions to maximize the chance for safe landing of partially impaired aircraft. Under DACS, there were research projects exploring the possible roles of propulsion to assist the flight control system in safely operating a damaged aircraft. One of the projects, "Commercial Engine Damage Assessment and Reconfiguration (CEDAR)," investigated how to continue to operate and maintain the necessary thrust of a slightly damaged engine under an emergency situation where engine shut down is not an option. This is a commercial version of a previous successfully demonstrated Naval Air Systems Command (NAVAIR) project "Survivable Engine Control Algorithm Development (SECAD) (ref. 5)." Another project under DACS was "Damaged Aircraft Good Engine (DAGE)" where the research focused on the propulsion system's role in aircraft control by re-examining the engine operating envelope and whether a higher performing engine can be used to help control and land the damaged aircraft under adverse conditions. "Resilient Propulsion Control," the propulsion element under the "Integrated Resilient Aircraft Control (IRAC)” project of the new NASA Aviation Safety Program, is built on the foundations laid by these predecessors. In the new re-programming of NASA Aeronautics Research, the IRAC project was proposed under the Aviation Safety Program to cover a wide range of aircraft mishaps including the loss of control, which is one of the largest contributors to airplane fatalities (ref. 6). The main objective of the IRAC project is similar to the DACS project concerning how to control and safely land an aircraft under adverse conditions, but the scope of the aircraft damage is extended to cover situations beyond the missile damage scenarios of the DACS project. Building upon the previously demonstrated research results such as PCA and TOC, the propulsion element under the IRAC project proposes to do research on how to best use the propulsion system to assist the flight control system under adverse conditions. This includes temporary engine operation enhancement beyond design limits, and exploration of integrated flight and propulsion control architectures to include the propulsion system as a redundant actuator for emergency operation.

This paper will first describe a high level analysis of requirements for the propulsion system in IRAC. A process to develop an engine simulation model and its controller are also described. We will then discuss the research area on the enhanced engine operations in high thrust and fast response operation. The impact on engine life and operability will also be discussed and a probabilistic risk assessment system proposed for the high level decision making process. Finally issues of integration with the flight control system will be discussed.

Figure 1 shows the concept for the propulsion system under IRAC. An intelligent propulsion system will continuously assess its health condition and remaining capabilities and report the status to the flight

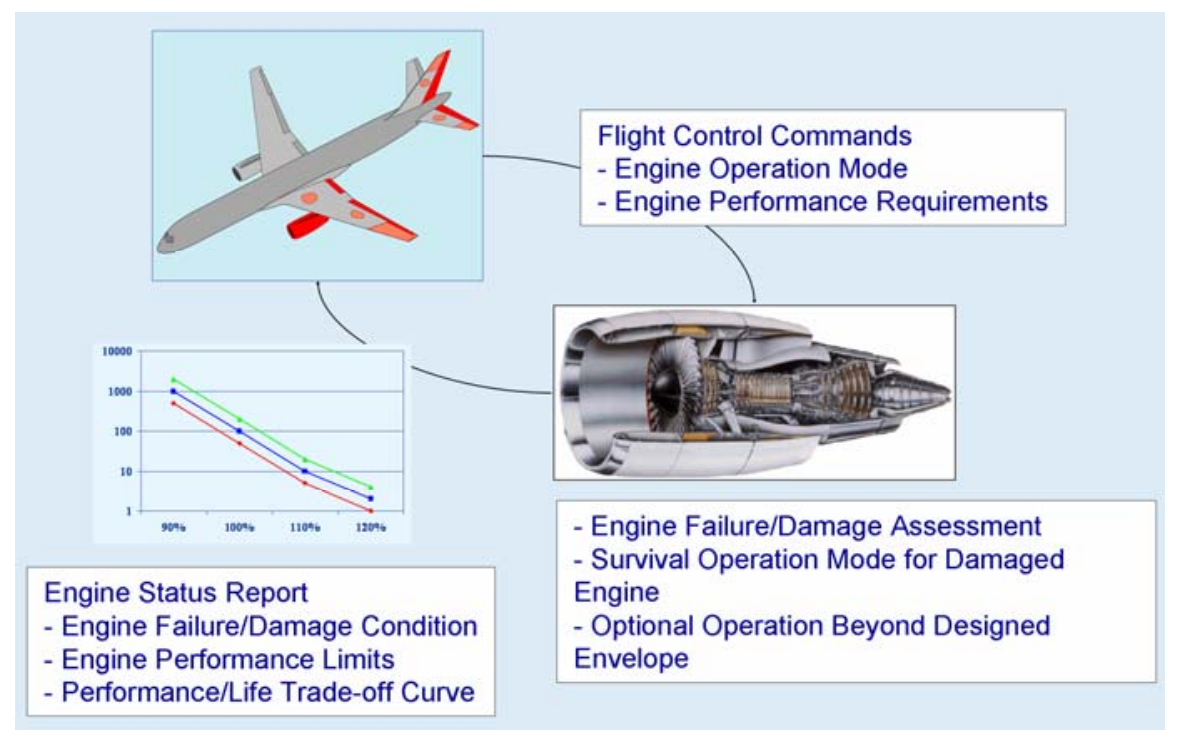

Figure 1.-Intelligent propulsion system concept for IRAC. 
controller. Depending upon the severity of the adverse condition, the integrated flight and propulsion control will select the engine operating modes according to the remaining capability of the propulsion system and the risk that the flight controller is willing to accept.

\section{System Requirements}

It is important to define a process to understand how and when the propulsion system can be used to assist the flight controller in providing a safer option beyond currently available solutions. The process requires a system level study to review and evaluate historical scenarios that involve aircraft accidents and incidents in which some or all flight surfaces are damaged or uncontrollable.

From these, the requirements for the propulsion system performance capabilities for a safe recovery and landing of an aircraft in adverse condition will be determined. In order to limit the study to a manageable set of cases, the airframes and engines will be limited to typical commercial aircraft configurations. The system level study will first identify the scenarios in which control of the damaged airframe is recoverable and the vehicle is able to maintain steady state flight. Once the survivability of the airframe in steady state is established, the next step is to identify the scenarios in which remaining dynamic resources are adequate for maneuvering and landing. Finally, for those scenarios in which the aircraft is structurally survivable, we will study the thrust level and throttle response needed to perform the maneuvers necessary to operate and land the damaged aircraft safely. This system study will produce a set of damage scenarios for which engine performance enhancement will be beneficial in a survivable landing. These results will also provide a guideline for the engine modeling and control research to achieve the performance enhancement requirements.

\section{Engine Modeling and Simulation}

In order to provide a platform for the intelligent propulsion control research, NASA Glenn Research Center is working with its industrial partners to develop a generic engine simulation package representative of a typical commercial turbofan engine. This development will also include a typical engine controller with protection logic to emulate engine control operations. This effort requires the collaboration of engine companies to provide engine performance characteristics and controller information.

Currently available engine simulations are only calibrated using sea level static testing data. To aid in the validation of engine characteristics during flight, NASA and its industrial partner have proposed a task for flight data collection of engine performance characteristics. A specially instrumented engine will be used to collect engine performance data to calibrate the engine models. This engine model calibration will provide a better understanding of the engine operation for the performance variations at different operating conditions. The data collected in the flight test will also help in understanding trends in performance characteristics general to turbofan engines across and beyond the traditional operational envelope even though it is specific to one engine configuration.

A generic engine controller has also been developed to mimic the functions of the Full Authority Digital Engine Control (FADEC) in engine operation. This includes all of the important protection logic affecting fan speed, core speed, fuel flow, temperatures, and pressures. This engine simulation will provide a starting platform for future developments to include other functionalities such as performance models, dynamic models, operability models, life usage models, and adaptive engine controls for flight integration. This engine simulation will also be incorporated as the basis for flight simulators at various NASA Centers to test the propulsion capability and the capability of the integrated flight and propulsion control under adverse conditions.

Figure 2 shows the vision of the engine modeling development and maturation process. The baseline engine model will be developed first. Enhanced engine models will be updated continuously depending upon the on-going research findings in the engine performance, life models, and operability

characteristics. The baseline engine operation simulation will be used in the early phase of the program to 


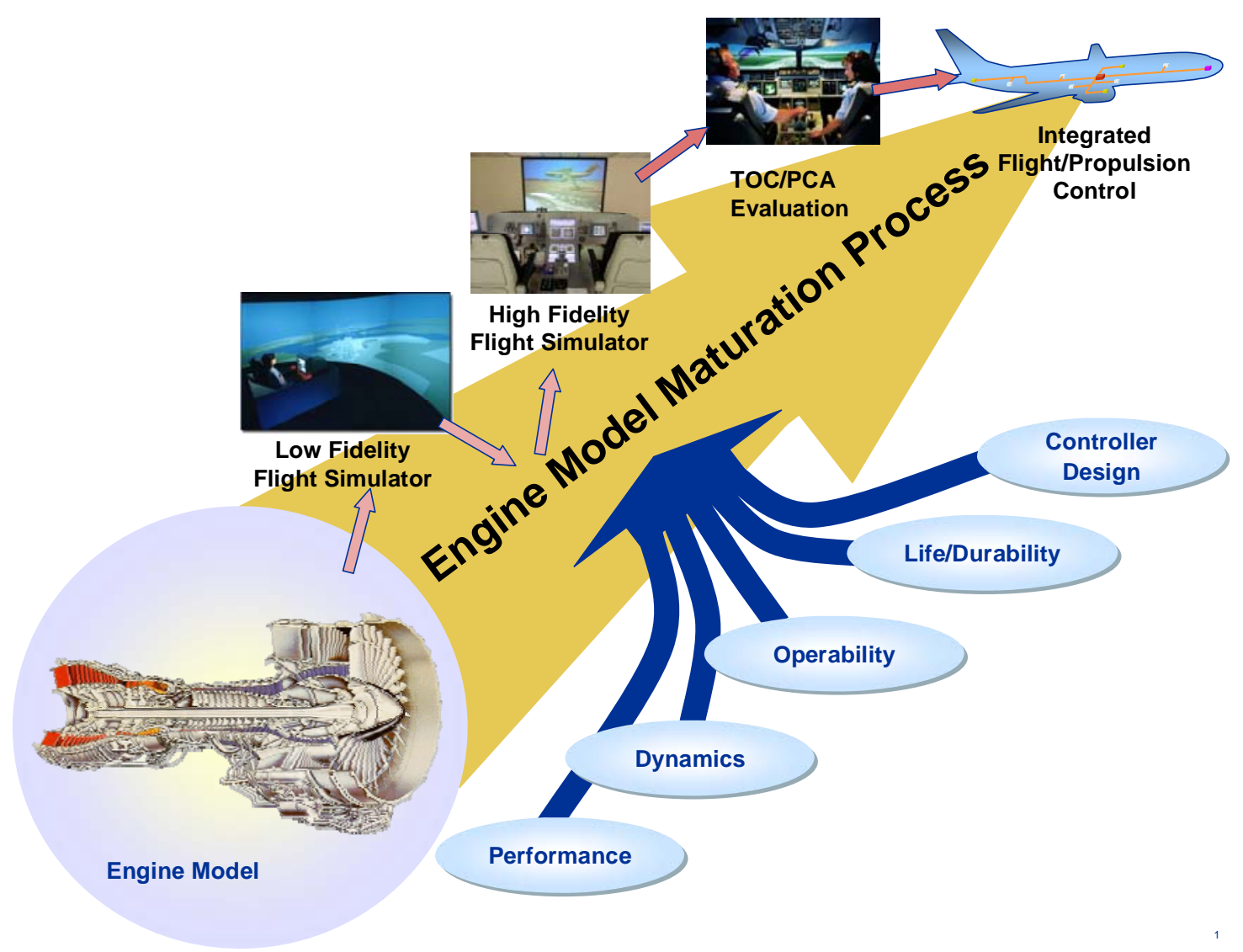

Figure 2.-Engine model maturation process.

generate the high level requirements for engine enhancement. After new models are developed for performance dynamics and operability, an upgraded engine simulation model with control strategies will be tested using the flight simulators at NASA Centers to evaluate the engine performance. Damaged engine operation capability will be demonstrated by injecting different types of discrete damage (simulated by degrading various internal engine model parameters) and adjusting the control parameters to continue operation and recover desired thrust.

The engine enhancement models will then be evaluated through a TOC study, since it does not require any software or hardware modifications to the flight simulator. This study will quantify the effects of enhanced engine performance on TOC over a set of damage scenarios. Based on this study, methods for creating and evaluating PCA control laws with an enhanced performance engine will be developed. The effects of both engine response enhancements (such as the relaxation of engine over-speed limits) and engine damage (such as restricted margins) on PCA performance will also be evaluated. This research will provide the foundation for the development and evaluation of a fully integrated flight/propulsion control system.

\section{Engine Enhancement Research}

Previous experience on the PCA study shows that the engine response time has a major impact on the ability of the pilot to handle the aircraft for a safe landing. Also, although the engines usually have a very high thrust reserve during normal flight, this is not necessarily the case for a damaged aircraft. In the DAGE study, when a 757-like aircraft lost about 15 percent of the wing, it was demonstrated analytically that all the reserve thrust was required to keep the aircraft in steady state flight, and it would require more thrust to climb and maneuver the damaged aircraft. Thus, it is also necessary to explore overthrust 
operation to provide the flight controller another option for maximizing the chance of a safe landing under adverse conditions.

Research on engine dynamics will focus on the understanding and characterization of the transient engine response under various operating conditions. The flight data collection task mentioned in the Engine Modeling and Simulation section will also be used to estimate the engine dynamic response capability at various flight conditions. It can help provide understanding of the limitations as well as reveal opportunities for improving engine dynamic response. Engine performance research also includes Computational Fluid Dynamic (CFD) modeling for the stage by stage gas dynamics of engine operation in order to simulate engine transient characteristics for given operating conditions. This study will provide an important understanding about how to improve engine response time at key operating conditions such as during approach and landing (low power, low altitude). Other actuators such as bleed valves and guide vanes will also be examined for possible improvement of the dynamic response. Additionally, NASA will be working with industry partners on the development of a dynamic model under Numerical Propulsion System Simulation (NPSS).

Models of engine operation beyond the normal flight envelope will also be developed. These studies will include accurate thrust representations at high inlet distortion conditions beyond the typical airplane upset condition. Engine operational characteristics beyond the design limits will also be studied in detail. This research result will provide a basis for the controller design for over-thrust engine operation.

There will also be research on engine damage modeling for selected conditions such as foreign object damage (FOD), blade-out, and other damage scenarios. In order to provide possible continued operation of a damaged engine, this research will model the external damage that affects engine performance to simulate a slightly damaged but still operable engine. This study is based on a continuation of the previous NASA/GE CEDAR project under the Aviation Safety \& Security Program. The CEDAR project has been a collaboration with both Wright Patterson Air Force Base (WPAFB) and NAVAIR.

\section{Operational Risk Analysis and Modeling}

The primary objective of this research is to understand and quantify the risk involved in enhanced engine operation for better performance. This includes the study of possible failure modes associated with the enhanced engine operation, life modeling of the critical components, and operability margin management. Because of the stochastic nature of the failures, it is also necessary to develop a quantitative representation tool to describe risks involved.

The engine state plays an important role in how the engine operates. For example, a new engine will have much more thrust in reserve, be more responsive, and much less likely to fail when operated in an enhanced mode than an older engine. A "life meter" has been proposed to track the component life usage and to derive the likelihood of the failure on the next flight. This "life meter" would also be able perform a prognosis of the probability of failure for the intended enhanced operation.

A system level failure mode analysis will be conducted for each control constraint in the engine controller and the likely failure modes that may impact engine operation will be identified. Life models associated with the critical components will be developed. Stochastic life models will be obtained using Monte Carlo simulations. Trade studies of engine performance, dynamics, operability constraints, and engine life consumption will be conducted.

Another important engine parameter is the operability which includes the fan and compressor stability margins, inlet stability, and combustor stability. The operability study in this project will investigate the parameters and conditions that affect these stability margins. An on-line estimation capability will be developed. This is an important element for enhanced engine operation during the performance and safety trade-offs. NASA's past research in the High Stability Engine Control (HISTEC) program provides some initial study on the stability management (ref. 7).

An important research topic under this life-for-performance study is the understanding of different

forms of risk. The risks involved here include different failure mechanisms with different severities for critical components, and the operability margins with different implied safety consequences. This 


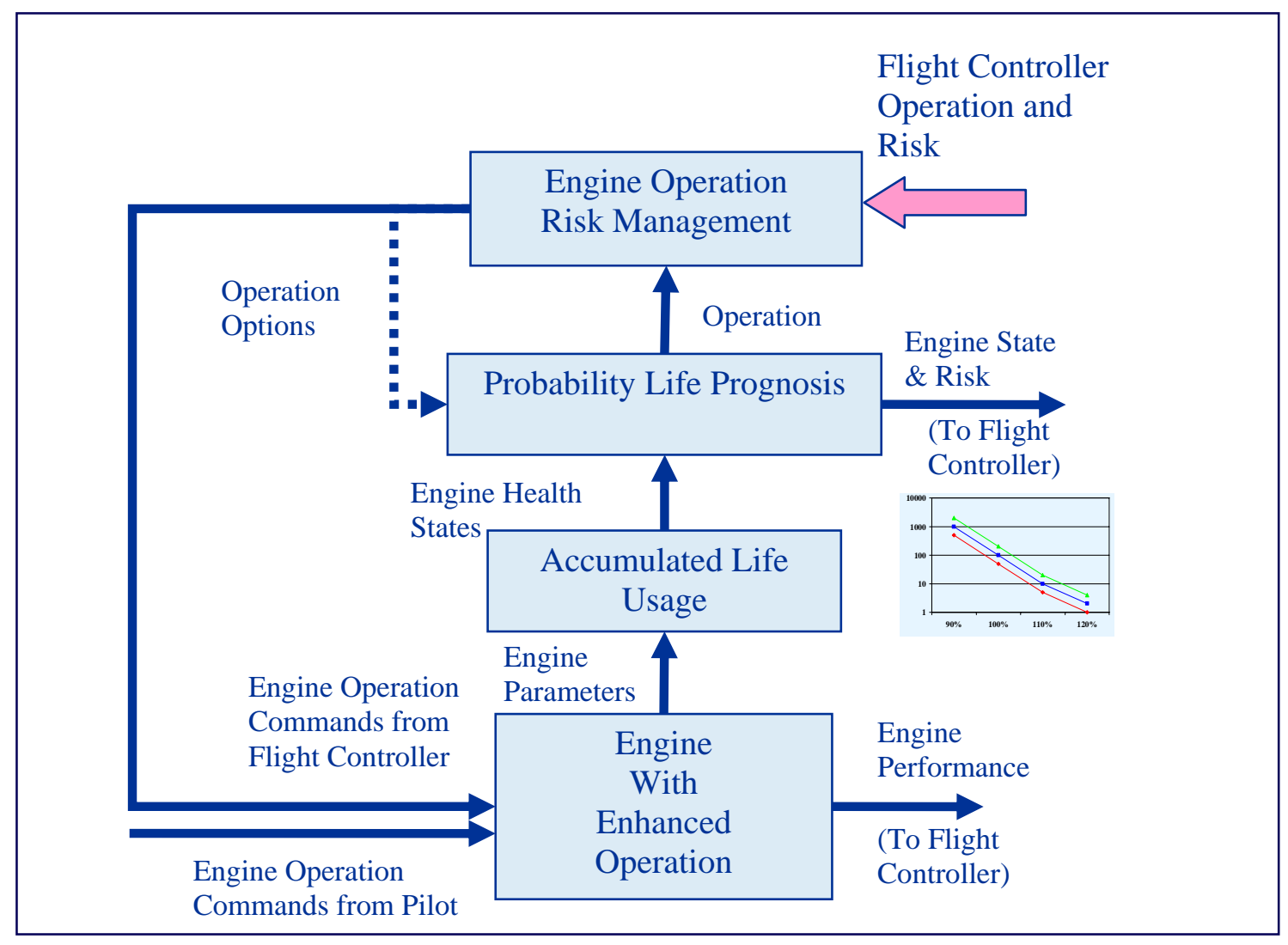

Figure 3.--Risk evaluation at engine level.

description of risk will ultimately be communicated to the flight and mission levels for decision making on how to optimize the chance of safely recovering an aircraft from upset conditions.

Figure 3 shows the information flow required for the risk management task in operating an engine in an enhanced mode. In figure 3, engine life usage is monitored to assess the condition of the engine. The engine health condition is used by the probability life prognosis module to evaluate the risk profile of control options selected by the flight controller. The engine state and risk information is then used by the flight controller in the high level decision making to maximize the chance for a successful recovery and landing under adverse conditions.

\section{Integrated Flight and Propulsion Control}

The challenge of this research area is to develop a flexible control architecture that will be able to execute the aforementioned engine performance enhancing capabilities, which include thrust boost, faster response, and damaged engine operation. The designed controller shall also be able to seamlessly transition from normal operation to an emergency operating mode, and from one emergency mode to another emergency mode.

In order to develop the control strategies for the engine enhancing capabilities, the limits implemented in the current controller will be studied to understand their impacts on performance when those limits are relaxed. A perturbation study of these control limits will provide the basis for an initial control strategy design for enhanced engine operation. These perturbation study results will also be used to investigate the component lifing issues associated with these operations. It is also important to understand and monitor the operability margins when engines are flown with the modified control requirements, especially when trying to improve the responsiveness of the engine. 
Another area of control study is the manipulation of control actuators that are usually scheduled during the flight. These actuators include variable stator vanes, bleed valves at different stages, custom bleed valves, and the Active Clearance Control (ACC). It is important to study all possible options in the emergency operation of engine because the priority changes with the safety and performance considerations.

One of the important functions of the adaptive engine control is the thrust management for integrated flight/propulsion control. The thrust management function lets the engine controller play an active role in

flight control. This can include receiving direct commands from the flight controller for differential thrust to utilize the engine pair as a redundant set of flight actuators. The thrust management will also include the life/performance trade-off evaluation and optimization for the constraints specified by the flight controller.

\section{Summary}

In this paper we have laid out a road map for a new propulsion research area for the IRAC project under NASA Aviation Safety Program. The goal of the IRAC project is to improve the likelihood of safe landing of a damaged airplane, and the propulsion element supports that goal by enabling the engines to act as responsive flight control actuators. This area includes fundamental research on how to improve the engine thrust response and thrust level performance for an emergency operation in order to achieve safe landing of an aircraft under adverse conditions. The paper also discussed the research needed to develop an understanding of the operational risks involved when the engine is operated beyond its normal limits. The risks involved include the component failures and operability margins. The control design is also critical for a successful implementation of the integrated flight and propulsion control. The IRAC project is a five year project that requires the close collaboration of government, industry, and academia in both fundamental and applied research.

\section{References}

1. National Transportation Safety Board, “Aircraft Accident Report, United Airlines Flight 232, McDonnell Douglas DC-1040, Sioux Gateway Airport, Sioux City, Iowa, July 19, 1989,” PBSO910406, NTSB/AAR-SO/06, 1990.

2. Lemaignan, B., "Flying with no Flight Controls: Handling Qualities Analyses of the Baghdad Event," AIAA-2005-5907, AIAA Atmospheric Flight Mechanics Conference and Exhibit, San Francisco, CA, Aug. 15-18, 2005.

3. Burcham, F.W., Jr.; Maine, Trindel A., Burken, John; Pappas, Drew, "Development and Flight Test of an Augmented Thrust-Only Flight Control System on an MD-11 Transport Airplane,” AIAA1996-3742, Guidance, Navigation and Control Conference, San Diego, CA, July 29-31, 1996.

4. Burcham, Frank W., Fullerton, C. Gordon, and Maine, Trindel A., "Manual Manipulation of Engine Throttles for Emergency Flight Control,” NASA/TM-2004-212045, January 2004.

5. Frankenberger, C.E., III, "Survivable Engine Control Algorithm Development (SECAD)," Proceedings of the 2002 IEEE Aerospace Conference, vol. 6, 2002, pp. 6-3015-6-3020.

6. "Statistical Summary of Commercial Jet Airplane Accidents-Worldwide Operations 1959-2001," Airplane Safety, Boeing Commercial Airplane, Seattle, WA, USA, 2002, p. 16.

7. DeLaat, John C., Southwick, Robert D. and Gallops, George W., "High Stability Engine Control (HISTEC),” NASA Technical Memorandum 107272, AIAA-96-2586, 32nd Joint Propulsion Conference, Lake Buena Vista, Florida, July 1-3, 1996. 


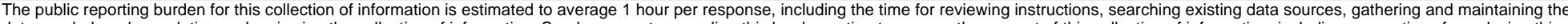

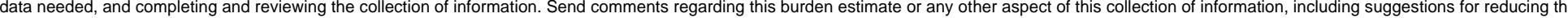

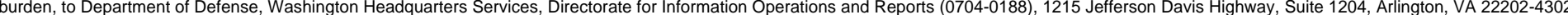

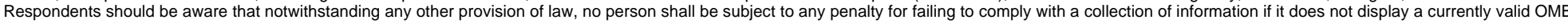
control number.

PLEASE DO NOT RETURN YOUR FORM TO THE ABOVE ADDRESS.

\section{REPORT DATE (DD-MM- $Y Y Y Y)$ \\ 2. REPORT TYPE \\ 3. DATES COVERED (From - To)}

01-08-2007

\section{TITLE AND SUBTITLE}

Technical Memorandum

Resilient Propulsion Control Research for the NASA Integrated Resilient Aircraft Control

(IRAC) Project

\section{5a. CONTRACT NUMBER}

5b. GRANT NUMBER

5c. PROGRAM ELEMENT NUMBER

\section{AUTHOR(S)}

Guo, Ten-Huei; Litt, Jonathan, S.

\section{5d. PROJECT NUMBER}

5e. TASK NUMBER

5f. WORK UNIT NUMBER

WBS 457280.02.07.03.01

\section{PERFORMING ORGANIZATION NAME(S) AND ADDRESS(ES)}

National Aeronautics and Space Administration

\section{PERFORMING ORGANIZATION}

REPORT NUMBER

John H. Glenn Research Center at Lewis Field

E-16127

Cleveland, Ohio 44135-3191

\section{SPONSORING/MONITORING AGENCY NAME(S) AND ADDRESS(ES)}

National Aeronautics and Space Administration

Washington, DC 20546-0001

and

U.S. Army Research Laboratory

Adelphi, Maryland 20783-1145

\section{TO. SPONSORINGIMONITORS ACRONYM(S) \\ NASA; ARL}

11. SPONSORING/MONITORING REPORT NUMBER

NASA/TM-2007-214940; ARL-TR-4131

\section{DISTRIBUTIONIAVAILABILITY STATEMENT}

Unclassified-Unlimited

Subject Categories: 07 and 63

Available electronically at http://gltrs.grc.nasa.gov

This publication is available from the NASA Center for AeroSpace Information, 301-621-0390

\section{SUPPLEMENTARY NOTES}

\section{ABSTRACT}

Gas turbine engines are designed to provide sufficient safety margins to guarantee robust operation with an exceptionally long life. However, engine performance requirements may be drastically altered during abnormal flight conditions or emergency maneuvers. In some situations, the conservative design of the engine control system may not be in the best interest of overall aircraft safety; it may be advantageous to "sacrifice" the engine to "save" the aircraft. Motivated by this opportunity, the NASA Aviation Safety Program is conducting resilient propulsion research aimed at developing adaptive engine control methodologies to operate the engine beyond the normal domain for emergency operations to maximize the possibility of safely landing the damaged aircraft. Previous research studies and field incident reports show that the propulsion system can be an effective tool to help control and eventually land a damaged aircraft. Building upon the flight-proven Propulsion Controlled Aircraft (PCA) experience, this area of research will focus on how engine control systems can improve aircraft safe-landing probabilities under adverse conditions. This paper describes the proposed research topics in Engine System Requirements, Engine Modeling and Simulation, Engine Enhancement Research, Operational Risk Analysis and Modeling, and Integrated Flight and Propulsion Controller Designs that support the overall goal.

\section{SUBJECT TERMS}

FADEC; Control; Turbofan; Lifing; Integrated flight and propulsion control

\begin{tabular}{|c|c|c|c|c|}
\hline \multicolumn{3}{|c|}{ 16. SECURITY CLASSIFICATION OF: } & \multirow{2}{*}{$\begin{array}{l}\text { 17. LIMITATION OF } \\
\text { ABSTRACT }\end{array}$} & \multirow{2}{*}{$\begin{array}{l}\text { 18. NUMBER } \\
\text { OF } \\
\text { PAGES } \\
13\end{array}$} \\
\hline $\begin{array}{l}\text { a. REPORT } \\
\mathrm{U}\end{array}$ & $\begin{array}{l}\text { b. ABSTRACT } \\
U\end{array}$ & $\begin{array}{l}\text { c. THIS } \\
\text { PAGE } \\
\text { U }\end{array}$ & & \\
\hline
\end{tabular}

\begin{tabular}{l} 
19a. NAME OF RESPONSIBLE PERSON \\
Jonathan S. Litt \\
\hline 19b. TELEPHONE NUMBER (include area code) \\
216-433-3748
\end{tabular}



